\title{
MIXED INFECTIVE ENDOCARDITIS IN A HEROIN ADDICT
}

\author{
J. A. Child*, J. H. Darrell, N. Rhys Davies AND \\ L. Davis-Dawson
}

Department of Medicine, Central Middlesex Hospital, and Departments of Bacteriology and Clinical Cardiology, Royal Postgraduate Medical School, Hammersmith Hospital, London

THE recent increase in drug addiction in the United Kingdom, particularly in young people addicted to heroin, has led to an acute awareness of infective complications of intravenous self-administration (" main-lining "), previously extensively documented in American literature (Hussey et al., 1944; Luttgens, 1949; Hussey and Katz, 1950; Cherubin, 1967; and Louria, Hensle and Rose, 1967). In a review of 48 cases of endocarditis in addicts, Louria et al. noted the high mortality of this complication. Staphylococci are frequently the infecting agents, and the occurrence of septic pulmonary infarcts in heroin addicts with staphylococcal tricuspid endocarditis has been reported by several authors (Hussey and Katz; Wilder, 1957; and Olsson and Romansky, 1962). Briggs et al. (1967) recently described severe systemic infections in 11 drug addicts admitted to London hospitals. Although several of the patients probably had multiple septic pulmonary infarcts, there was no good evidence of endocarditis. The present paper reports an apparent bacteriological cure, after $5 \mathrm{mth}$ of continuous antimicrobial therapy, of a young heroin addict from whom four different bacterial species were isolated; the patient probably had bacterial endocarditis affecting the right side of the heart and there were septic pulmonary complications.

\section{CASE REPORT}

P. A., aged 19, had been a drug addict for $5 \mathrm{yr}$; he was originally introduced to "purple hearts" and shortly afterwards to heroin. There was a disturbed family background, but until the age of $14 \mathrm{yr}$ he had done well at school and was being prepared for university entrance. There was a steady increase in his use of heroin, usually self-administered intravenously with non-sterile apparatus. Although a " registered" addict, he also obtained drugs illicitly and, at times, took as much as 12 grains $(0.75 \mathrm{~g})$ of heroin daily. In January 1967 he was admitted to Shenley Psychiatric Hospital and taken off drugs, but he was readmitted in May 1967 when he had resumed the practice of taking heroin. Again he was weaned off the drug, on this occasion by methadone substitution. He absconded from hospital on several occasions, returning to his old haunts in order to obtain drugs. In September 1967 he was found to be pyrexial and

Received 9 Nov. 1968; accepted 25 Nov. 1968.

* Present address: c/o Haematology Dept, St Bartholomew's Hospital, London, E.C.1.

J. MED. MtCROBIOL.-VOL. 2 (1969) 


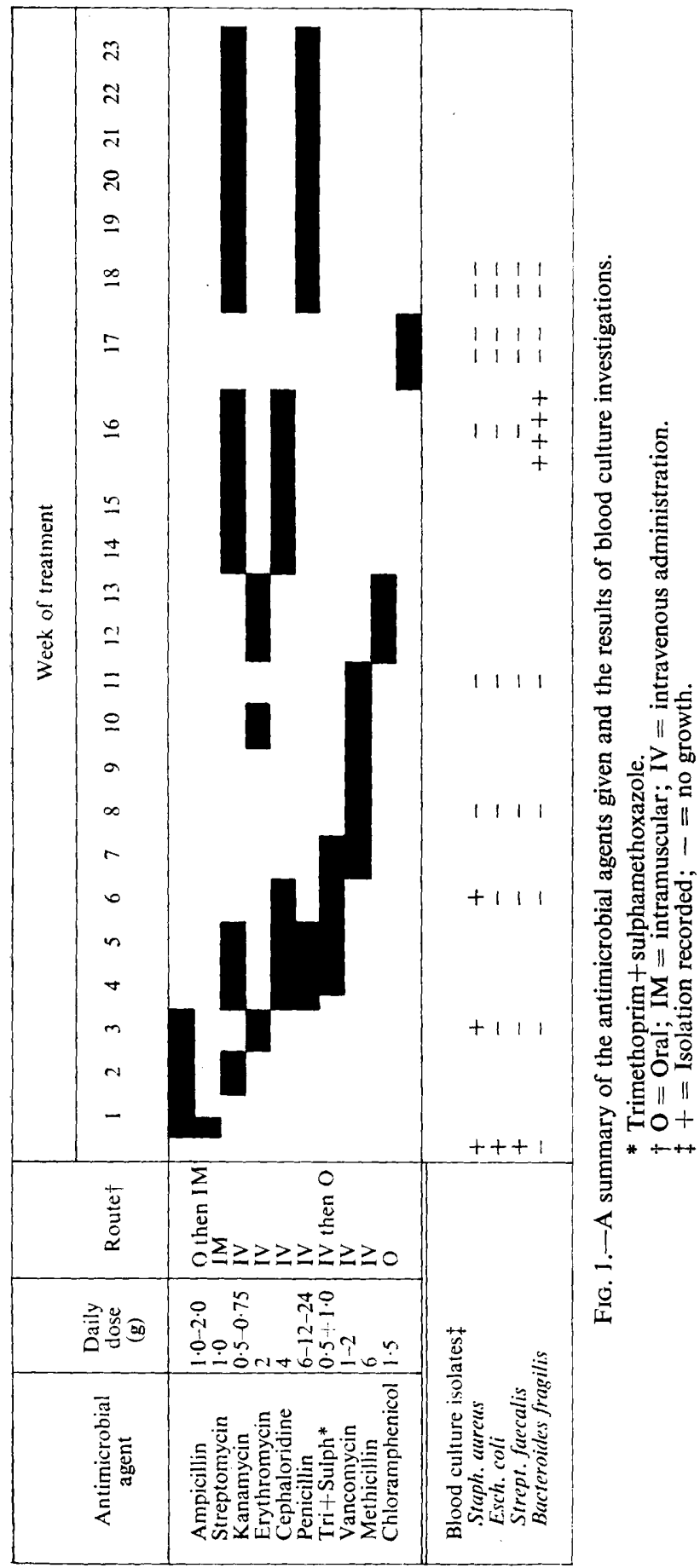


an initial diagnosis of pneumonia was made; he was treated accordingly with benzylpenicillin, but it was subsequently realised that he had developed bacterial endocarditis with pulmonary emboli. He was then transferred to the Central Middlesex Hospital, at which time he had a swinging pyrexia and frequent rigors.

On examination he was pyrexial, anaemic and obviously extremely ill. There was a grade-II pansystolic murmur at the left sternal border, accentuated by inspiration, indicative of tricuspid regurgitation. There were no subungual splinter haemorrhages, no finger-clubbing and the spleen was impalpable. Venous pressure in the neck was not raised. There was no evidence of phlebitis.

Investigations. Haemoglobin 60 per cent., WBC 8800 per $\mathrm{mm}^{3}$. Urine: protein nil, glucose nil. Blood urea $26 \mathrm{mg}$ per $100 \mathrm{ml}$. Creatinine clearance $90 \mathrm{ml}$ per min. Blood cultures yielded a mixed growth of Staphylococcus aureus, Streptococcus faecalis and Escherichia coli. Chest X-ray showed scattered opacities with central cavities in both lung fields. E.C.G.: sinus tachycardia, otherwise normal.

Treatment. Antibiotic treatment is summarised in fig. 1, which shows doses and routes of administration. Initial treatment with ampicillin and streptomycin was followed by ampicillin and kanamycin, then ampicillin alone for a few days and subsequently ampicillin and erythromycin. After 3 weeks' treatment and while the patient was still receiving the latter combination, blood culture yielded Staph. aureus alone. Treatment was changed to cephaloridine with kanamycin. Benzylpenicillin was also given because of its greater activity against faecal streptococci. After a week the patient's bacteriaemia remained uncontrolled. Penicillin was stopped and trimethoprim and sulphamethoxazole were given along with the remaining antibiotics. There was a transient improvement with this regimen, but the fever recurred and Staph. aureus was again isolated. Vancomycin was now given and staphylococci were not subsequently isolated from blood cultures; the patient's condition, however, remained essentially unchanged. Erythromycin was added to the vancomycin, but fever persisted, and he continued to have rigors. He received several fresh blood transfusions.

On the assumption that we were still dealing with a staphylococcal endocarditis that had been suppressed but not cured, methicillin was given. Combined treatment was thought to be essential and, as the patient had already had prolonged treatment with kanamycin, erythromycin was again used. After a further 2 wk with no sustained clinical improvement, treatment was changed yet again and we reverted to cephaloridine and kanamycin. It was felt that the patient had perhaps done better with this than with any other combination.

In view of prolonged, persistent fever, the patient was transferred to Hammersmith Hospital, for consideration of surgical replacement of the infected valve. The degree of damage to the tricuspid valve was not sufficient to warrant valve repair or replacement for haemodynamic reasons and it was therefore decided to continue to attempt cure of the infection by medical means. Furthermore, although it was highly probable that there was infection 


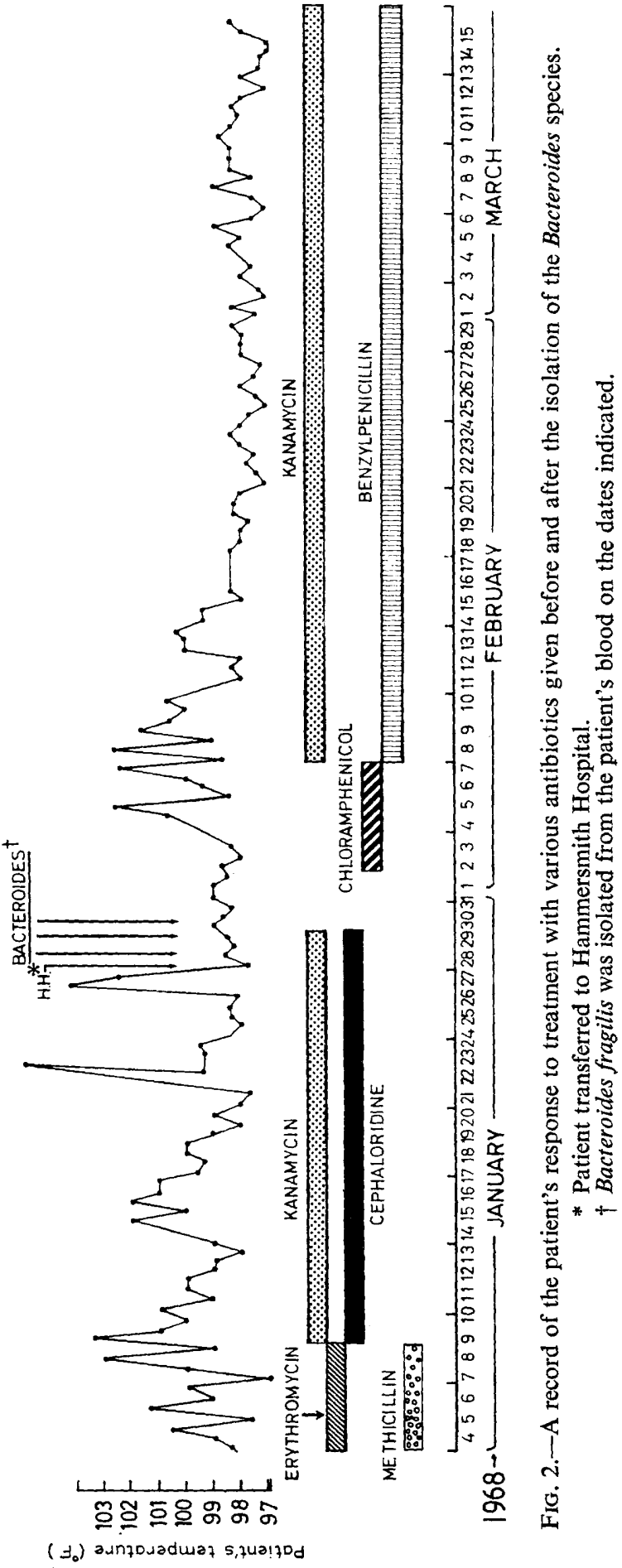


of the tricuspid valve, the diagnosis could not be made with absolute certainty.

As a preliminary, it was decided to stop all antibiotics. Blood cultures immediately before and after this yielded Bacteroides fragilis. While further bactericidal tests were done, the patient was given chloramphenicol, erythromycin having been previously used without effect. The chloramphenicol was soon replaced by large doses of benzylpenicillin, with probenicid. Kanamycin was also given, as combined treatment was again thought to be advisable.

Clinical progress. The patient became afebrile 4 days after the start of this last course of treatment and all evidence of active infection subsequently disappeared. The chest radiographic appearances cleared and the signs of tricuspid regurgitation were minimal. The latter part of the patient's progress is recorded in fig. 2. Treatment was continued for $6 \mathrm{wk}$.

TABLE

Results of tube tests of combined bactericidal action of mixtures of antibiotics against the Bacteroides fragilis strain isolated

\begin{tabular}{|c|c|c|c|c|c|c|c|c|}
\hline \multirow{2}{*}{$\begin{array}{l}\text { Antibiotic I and test } \\
\text { concentration } \\
(\mu \mathrm{g} \text { per ml) }\end{array}$} & & \multicolumn{7}{|c|}{$\begin{array}{l}\text { Amount of growth on subculture* after overnight incubation } \\
\text { of the test strain in broth containing the stated antibiotic I } \\
\text { combined with }\end{array}$} \\
\hline & & Pen. & Ery. & Lin. & Gen. & Kan. & Nov. & Chlor. \\
\hline $\begin{array}{l}\text { Penicillin (Pen.) } \\
\text { Erythromycin (Ery.) } \\
\text { Lincomycin (Lin.) } \\
\text { Gentamicin (Gen.) } \\
\text { Kanamycin (Kan.) } \\
\text { Novobiocin (Nov.) } \\
\text { Chloramphenicol (Chlor.) }\end{array}$ & $\begin{array}{l}25 \\
10 \\
10 \\
10 \\
10 \\
10 \\
10\end{array}$ & $\begin{array}{l}1 \mathrm{c} \\
\cdots \\
\cdots \\
\cdots \\
\cdots \\
\cdots\end{array}$ & $\begin{array}{c}(+) \\
(+) \\
\cdots \\
\cdots \\
\cdots \\
\cdots \\
\cdots\end{array}$ & $\begin{array}{l}(+) \\
(+) \\
(+) \\
\cdots \\
\cdots \\
\cdots \\
\cdots\end{array}$ & $\begin{array}{c}\overline{+} \\
+ \\
+++ \\
\ldots \\
\ldots\end{array}$ & $\begin{array}{l}\overrightarrow{+} \\
+ \\
+ \\
+++ \\
+++ \\
\quad \ldots \\
\quad \cdots\end{array}$ & $\begin{array}{l}+ \\
+ \\
+ \\
+++ \\
+++ \\
++ \\
+\end{array}$ & $\begin{array}{l}++ \\
+ \\
+ \\
++ \\
++ \\
++ \\
++\end{array}$ \\
\hline
\end{tabular}

$*+++=$ Growth evident by increased turbidity of test broth; $++=$ growth obtained on subculture equivalent to control subculture of test inoculum, i.e., bacteriostasis, but no demonstrable bactericidal effect; $+=$ reduced number of colonies obtained on subculture; $(+)=$ much reduced number of colonies on subculture; $1 \mathrm{c}=1$ colony on subculture; $-=$ no growth (total bactericidal action).

\section{BACTERIOLOGICAL FINDINGS}

Blood cultures taken on admission yielded a mixed growth of Esch. coli, a faecal streptococcus, and Staph. aureus. After treatment for $3 \mathrm{wk}$, blood culture yielded Staph. aureus alone. The original strain had been resistant to benzylpenicillin only, but the subsequent isolate, though of the same phage type $(6 / 54 / 75+)$, was also resistant to streptomycin. The patient's condition remained essentially unchanged by further treatment, including trimethoprim with sulphamethoxazole, and the staphylococcus was again isolated from blood cultures. After vancomycin was administered staphylococci were not subsequently isolated, but the patient was not clinically improved. It was decided to stop antibiotic treatment, as a preliminary to possible heart surgery, in order to obtain a fresh isolate of the staphylococcus. One culture immediately before and four taken after stopping antibiotics yielded Bacteroides fragilis 
from all bottles. The organism was resistant to penicillin, streptomycin, tetracycline and sulphonamide, but sensitive to erythromycin and chloramphenicol. The minimum inhibitory concentration (MIC) of benzylpenicillin for the organism was $8 \mu \mathrm{g}$ per ml. A tube test of combined bactericidal action showed the action of chloramphenicol to be purely bacteriostatic, whilst erythromycin and lincomycin caused incomplete killing (table). Benzylpenicillin alone, in high concentration $(25 \mu \mathrm{g}$ per $\mathrm{ml})$, was almost completely bactericidal: a single colony grew on subculture. Intravenous treatment was started with $12 \mathrm{~g}$ penicillin daily and $0.5 \mathrm{~g}$ kanamycin daily. This dose of penicillin was considered to be inadequate and was doubled, and probenicid was given. The concentration of penicillin in the patient's serum was determined on two occasions at this stage and found to be $82 \mu \mathrm{g}$ and $65 \mu \mathrm{g} \mathrm{per} \mathrm{ml}$. All blood cultures taken after the institution of this regimen were sterile.

\section{DisCUSSION}

Addicts are known to use water from water closets in preparing drugs for self-administration, as public lavatories provide the necessary privacy with a source of water.

It is likely that the mixture of organisms isolated from this patient represents faecal contamination, and that the Bacteroides was present from the onset and established itself after the other species had been eradicated. It is also possible that later attempts to isolate organisms from the blood were directed rather too single-mindedly to isolating staphylococci. In many cases pour plates only were prepared and were not necessarily kept long enough to allow Bacteroides to grow, even if the organism was present. The question arises as to whether the Bacteroides represents a reinfection due to continued selfinjection while in hospital. The opportunities for this were not great, as, for much of the time, the patient was confined to bed for intravenous therapy. Also the persistent fever indicates an uncontrolled infection, which was in all probability due to Bacteroides.

Staphylococcus aureus has replaced the Candida species, classically described as the most important cause of infective complications in addicts. Staphylococcal infections respond well to vancomycin (Louria et al., 1967). This case poses the problem of the management of mixed bacteriaemias and of the treatment of severe infections with Bacteroides species. The action of chloramphenicol was shown to be purely bacteriostatic in vitro and during treatment with this drug the patient's condition worsened. Although Ingham et al. (1968) have successfully treated severe infections due to $B$. fragilis with erythromycin, and though erythromycin and lincomycin showed considerable, though incomplete bactericidal activity against the bacteroides strain in the present case, three courses of erythromycin, given parenterally in adequate doses ( $2 \mathrm{~g}$ daily) failed to cure our patient. Low doses of benzylpenicillin have no effect on B. fragilis, but high doses were all but completely bactericidal in vitro for this strain. It is possible that in the dose used, penicillin alone would have cured this patient's very protracted valve infection. 


\section{SUMMARY}

A case of bacterial endocarditis with septic pulmonary embolism in a heroin addict, from whom four different bacterial species were isolated, is reported. Apparent bacteriological cure was achieved after $5 \mathrm{mth}$ of intensive therapy. It seems that successful treatment was not achieved until an underlying infection with Bacteroides fragilis was detected and antibiotic therapy was adjusted accordingly.

We wish to thank Dr J. P. Knowles, under whose care the patient was admitted to the Central Middlesex Hospital, and Professor J. F. Goodwin of Hammersmith Hospital for allowing us to publish this case. Our thanks are also due to Miss Pamela Waterworth who performed the bactericidal sensitivity tests and antibiotic assays.

\section{REFERENCES}

Briggs, J. H., McKerron, C. G., 1967. Lancet, 2, 1227.

SOUHAMI, R. L., TAYLOR, D. J. E., AND

ANDREWS, Hilary

Cherubin, C. E. .

1967. Ann. Intern. Med., 67, 23.

Hussey, H. H., ANd Katz, S. . . . 1950. Amer. J. Med., 9, 186.

Hussey, H. H., Keliher, T. F., Schaefer, 1944. J. Amer. Med. Assoc., 126, 535.

B. F., AND WALSH, B. J.

Ingham, H. R., Selkon, J. B., Codd, 1968. J. Clin. Path., 21, 432.

A. A., ANd Hale, J. H.

Louria, D. B., Hensle, T., AND Rose, J. 1967. Ann. Intern. Med., 67, 1.

Luttgens, W. F.. . . . . 1949. Archs Intern. Med., 83, 653.

Olsson, R. A., ANd Romansky, M. J. . 1962. Ann. Intern. Med., 57, 755.

Wilder, R. M., JR . $\quad$. $\quad$. . 1957. Amer. J. Med., 23, 325. 